\title{
Vida y Muerte en Pablo Neruda: dos poemas del "Canto General"
}

Hay dos poemas del Canto General ("La muerte", de "El gran océano" [XIV]; y "El empalado", de "Los libertadores" [IV]), que a pesar de su diferente asunto (el primero es una sucesión de imágenes sobre la muerte en el mar; el segundo es la historia de la muerte de Caupolicán), guardan cierta semejanza temática. En ambos es tratado el tema de la muerte, y mediante un análisis pormenorizado de los dos poemas, se puede determinar una visión que Neruda tiene de la muerte en el Canto General. Veamos primero el poema "La muerte":

\section{LA MUerte ${ }^{1}$}

1 Escualos parecidos a las ovas,

2 al naval terciopelo del abismo,

3 y que de pronto como angostas lunas

4 aparecéis con filo empurpurado:

5 aletas aceitadas en tiniebla,

6 luto $\mathrm{y}$ velocidad, naves del miedo

7 a las que asciende como una corola

8 el crimen con su luz vertiginosa,

9 sin una voz, en una hoguera verde,

10 en la cuchillería de un relámpago.

1 Puras formas sombrias que resbalan

2 bajo la piel del mar, como el amor,

3 como el amor que invade la garganta,

4 como la noche que brilla en las uvas,

1 Pablo Neruda, Obras completas. Buenos Aires, Editorial Losada, segunda edición, 1962), p. 626. 
5 como el fulgor del vino en los puñales:

6 anchas sombras de cuero desmedido

7 como estandartes de amenaza: ramos

8 de brazos, bocas, lenguas que rodean

9 con ondulante flor lo que devoran.

1. En la mínima gota de la vida

2 aguarda una indecisa primavera

3 que cerrará con su sistema inmóvil

4 lo que tembló al caer en el vacío:

5 la cinta ultravioleta que desliza

6 un cinturón de fósforo perverso

7 en la agonía negra del perdido,

8 y el tapiz del ahogado recubierto

9 por un bosque de lanzas y murenas

10 temblorosas y activas como el telar que teje

11 en la profundidad devoradora.

El poema está estructurado en tres partes. Cada parte es una estrofa diferenciada de las otras dos en cuanto a contenido. La primera estrofa es primordialmente expositiva y los escualos ascienden en busca de la presa. En la segunda toma iugar la muerte de la presa y se mencionan partes del cuerpo de la misma, restos del despedazamiento. La tercera estrofa concluye con el banquete final de los escualos y murenas en la "profundidad devoradora".

La muerte aparece concebida en términos de "El gran océano": la muerte marina. Neruda ha escogido el escualo o cazón, el más mortífero de los selacios. La expresión "parecidos a las ovas", al referirse a los escualos, tiene una doble significación. Elementalmente la simple comparación visual: el cazón, visto bajo la superficie del agua, recuerda a las ovas, estas algas filamentosas que generalmente crecen en las aguas cotrientes. En segundo término, va implícito un significado de color: las ovas, de un verde profundo, tienen el color del océano. Más tarde, en esta primera estrofa, se acentuará la nota de color al describirse el ámbito en que consuman su crimen los escualos como "una hoguera verde".

- Se hace una "estilización" de las ovas y se convierten en "naval terciopelo del abismo", esto es, textura de terciopelo del abismo naval, del océano. El escualo, instrumento de muerte, aparenta la suavidad del terciopelo. Una nueva imagen realza la belleza del animal: "Iunas angostas", sin duda con referencia a las aletas del cazón. Pero esa belleza ad- 
quiere una nota sombría al añadir que aparecen "con filo empurpurado": el filo de algo cortante va unido al color púrpura de la sangre. La imagen se repite más llanamente en el quinto verso de la segunda estrofa: "como el fulgor del vino en los puñales". En esta última se habla directamente de los puñales y el color de la sangre es ahora representado por el vino. En la tercera estrofa hay una última alusión al color de la sangre, esta vez expresada en forma mucho más compleja: "la cinta ultravioleta que desliza un cinturón de fósforo perverso". Lo interesante de estas tres imágenes es que aparecen graduadas a medida que avanza el poema y tienen significaciones diferentes. En la primera es el "filo empurpurado" sólo la amenaza de la muerte. En la segunda estrofa la alusión a la muerte es mucho más directa y el puñal (instrumento de muerte) refleja el vino (o sangre). En la tercera estrofa la muerte ha sido consumada. La "cinta ultravioleta" que se "desliza" como un "cinturón de fósforo perverso" del cuerpo del ahogado fija el momento del drama. Pero, por otra parte, las imágenes están intimamente asociadas, pues la "cinta ultravioleta" de sangre viene a corresponder más a la muerte producida por un filo cortante o un puñal, que a la que produce el cazón al devorar a mordidas el cuerpo. En otro aspecto, la luz ultravioleta es aquella constituida por los rayos invisibles del espectro luminoso que se extienden a continuación del color violado, por lo que constituiria dentro del poema, la idealización más absoluta del color de la sangre, color que, llegado a su máximo grado en el espectro, se convierte en rayos transparentes o invisibles. La luz ultravioleta provoca también, en algunos cuerpos, una fluorescencia denominada "luz negra". Esta "luz negra" o teórica sombra complementa la atmósfera sombría y lúgubre del poema. Pero la luz ultravioleta posee otra propiedad aún más singular: penetra los cuerpos en la misma forma en que lo hacen los rayos Rontgen $\circ \mathrm{X}$. Mientras que estos últimos son artificiales, los primeros son naturales y estamos involuntariamente expuestos a ellos como a la muerte misma. El puñal penctra el cuerpo de la misma manera que estos rayos de luz. El color de la singre está dado por el fósforo, que es generalmente de color rojo. Éste o el fósforo blanco producen combustión. Dicha idea nos remite al final de la primera estrofa, en que Neruda se refiere a la "hoguera verde", donde el color de la hoguera se asocia al color de la sangre. La imagen se completa con el adjetivo perverso aplicado a fósforo que da todo un mundo de sugerenciàs fatales. Este "fós. foro perverso", tomando fósforo en su sentido de fosforescencia, va sugestivamente incorporado a la idea de que el cazón, de piel fosforescente y brillante, es el instrumento perverso de la muerte. 
Después de los tres versos iniciales nos encontramos de inmediato con la muerte, objetivada en el cazón. Una serie de términos utilizados seguidamente dan el tono: las aletas aceitadas en tinieblat se convierten en algo siniestro; después el luto y la velocidad. La idea de velocidad se refuerza dos versos más adelante. Neruda hace ahora a los escualos "naves del miedo a las que asciende", "el crimen con su luz vertiginosa". Asciende a los escualos, esto es, se incorpora a ellos el crimen, con su luz vertiginosa. Podríamos verlo sencillamente como el crimen que se produce con la rapidez vertiginosa de la luz. El sustantivo luz enriquece la imagen, pues crimen va generalmente asociado con la palabra sombra. Físicamente, el movimiento rápido, vertiginoso, es característico del cazón. Pero si hiciéramos abstracción de algunas palabras y utilizáramos sólo aquéllas que nos dieran una intención de contenido, tendriamos una nueva significación, también aceptable dentro del contexto del poema. Veamos en el propio orden en que aparecen: asciende, crimen, luz.

En su medio ambiente asciende el crimen hacia la luz. El escualo, representante del crimen, asciende por la masa líquida del océano atraído por la sombra que sobre la superficie produce la luz al chocar con la presa que flota. Esta interpretación no desvirtúa a la otra de que el cazón produce el crimen "con su luz vertiginosa", sino que las dos se complementan, estando ambos significados implícitos en esos versos.

Los dos versos finales de la estrofa refuerzan los anteriores. El silencio del océano está dado por "sin una voz". La descripción del mar como "hoguera verde" es especialmente significativa. Como anoté antes, el verde es el color del océano. Sin embargo, al ser el océano una "hoguera verde", se une al color de éste el color de la hoguera, el rojo flamigeto de la sangre. El color resultante de "esta" muerte se mezcla así al color del medio ambiente.

En el verso final los escualos mueven, con la velocidad del relámpago, la cuchillería de sus aletas. Las cuchilladas producen la muerte; los cuchillos semejan aletas. Luego los cazones son instrumentos de muerte. Este silogismo es sintetizado en una imagen visual de extraordinaria rapidez; se puede decir que se mueve (la imagen) con la velocidad del escualo.

Neruda combina tres elementos básicos de la existencia humana: la vida (a ello me referiré posteriormente), el amor y la muerte. Veamos estos dos últimos en la segunda estrofa.

Hay en los versos iniciales una nueva alusión a los escualos: son ahora "pura formas sombrías que resbalan bajo la piel del mar". El 
adjetivo inicial podriamos tomarlo en su sentido de "pureza" $o$, si se quiere, de "nitidez": "nítidas" formas. Me inclino más hacia el significado de "completas" o "totales" formas sombrias que resbalan "bajo la piel del mar". Después de la imagen surge la comparación más inusitada: "camo el amor, como el amor que invade la garganta". Aunque la comparación nos parece gratuita, hay un recurso técnico que identifica no sólo los dos términos de esta primera comparación, sino el resto de la estrofa con ella y todas las partes de la estrofa entre sí.

Primero relaciona Neruda la muerte y el amor. Los escualos, "formas sombrías", resbalan bajo la superficie del mar. Hay un cambio de sustantivos y superficie se convierte en piel. Después, el amor invade la gargania. Al humanizar al mar con la palabra piel obran esas "formas sombrias", los escualos, como el amor, emoción que, al igual que una ola (emoción súbita), suele invadir la garganta. Escualos y amor tienen, pues, la cualidad del movimiento. Ambos se mueven en relación con un ámbito humano: la piel o la garganta respectivamente:

Los escualos son, en nueva comparación, como la noche, y entiéndase como noche etema, como muerte. La muerte (la noche) brilla, se refleja en las uvas. El producto de las uvas es el vino (la sangre) y éste, a su vez, se refleja en los puñales, instrumento de muerte. Continúa la estrofa, y la piel, antes parte del mar, sufre una mutación para convertirse en cuero, ahora parte del animal. El procedimiento es como sigue: primero el mar se humaniza, después se toma el elemento personificante, y se modifica, deshumanizándolo. Por último, dicho elemento se traslada a un objeto animado. Los cazones son, asi "anchas sombras de cuero desmedido". El adjetivo desmedido, muy nerudiano por lo inusitado, aplicado primariamente a cuero, puede, por extensión, aplicarse al verso siguiente. Si las sombras son de cuero desmedido son desmedidas las sombras en sí. Si estas sombras son como "estandartes de amenaza", la amenaza es desmedida a su vez. Pero la amenaza no termina con estas "sombras desmedidas". El crimen se consuma en esta segunda estrofa.

Los escualos han mutilado y despedazado el cuerpo. Mientras que se dedican "a lo que devoran", a la mejor parte, fragmentos y miembros del cuerpo ondulan en derredor: "ramos de brazos, bocas, lenguas"... La constante que encadena los distintos momentos de la estrofa es precisamente esta colocación de partes del cuerpo humano en distintos versos del poema: piel, garganta, cuero (además de la piel de algunos animales, cuero cabelludo), brazos, bocas, lenguas.

Los versos finales podrían tener otro sentido si entendiéramos que 
los escualos "son como "brazos, bocas y lenguas" que rodean lo que devotan. Seria esta explicación más llana y también aceptable. En su proceso devorador los escualos realizan ordenadamente varias funciones: apresan como si fueran brazos y arrancan miembros y pedazos y los devoran como si su cuerpo fuera sólo bocas y lenguas. No obstante, la comparaciôn nos lleva a pensar de inmediato en los disiecta membra del cuerpo destrozado de la presa.

En la última estrofa se emparejan la vida y la muerte. La muerte en relación con la vida no es contraste sino condición fundamental de csta última.

La "mínima gota de la vida" es la gota de esperma. La gota seminal no puede autofecundarse, de ahí que aguarde una primavera indecisa dependiente de una futura germinación. La primavera es simbólicamente el inicio de la vida. Esta primavera, esta vida "cerrará con su sistema inmóvil lo que tembló al caer en el vacio", o sea, someterá con su invariable sistema a aquella gota de vida potencial una vez germinada.

Neruda ve entonces la vida como un sistema inmóvil en su sentido de inamovible o inmutable, como algo que lleva en sí el mismo germen de la muerte. Aun antes de llegar a los versos 5, 6 y siguientes de esta estrofa en que la comparación entre vida y muerte es obvia, nos damos cuenta de ello a través de la utilización en el tercer verso del sugerente término inmóvil como calificativo de sistema. $\mathbf{L a}$ inmovilidad es la primera consecuencia ostensible de la muerte.

Los versos 5 y 6 de esta estrofa, además del sentido general que tienen dentro del poema, funcionan orgánicamente dentro de la estrofa como continuación de los anteriores. Ese sistema inmóvil, en el que Neruda ve la vida y la muerte, para ser inmóvil ha de ser también cerrado y no abierto o lineal. Esto está resuelto con la concepción de un sistema circular, "un cinturón" de fósforo perverso. Manteniendo para el "fósforo perverso" la significación de muerte, los versos 5 y 6 nos dirán que la vida es un hilo, una cinta invisible (recuérdese que los rayos y el color ultravioleta son invisibles) que en forma cíclica va a moverse circularmente para terminar con la muerte que llevaba en forma indecisa y latente la original "mínima gota de la vida".

A continuación se habla directamente del perdido y del abogado. En relación con este color violeta, ultravioleta o empurpurado a que se hace mención en varios momentos del poema, conviene aclarar que es éste precisamente el color que adquieren los ahogados. La cianosis produce el color negruzco en la sangre y, como consecuencia, violáceo en la piel. debido a la falta de oxígeno. 
El final del poema lo constituyen una imagen visual y algunos símiles. Los escualos fosforescentes : se mueven formando un círculo alrededor del "perdido", un "cinturón de fósforo perverso". La "agonía negra del perdido" es la agonía de la muerte. El ahogado está recubierto por lanzas y murenas activas "como el telar que teje en la profundidad devoradora". Por última vez en el poema introduce Neruda otra arma cfensiva que produce la muerte con su filo metálico: la lanza. Haciendo un recuento nos encontramos, en este orden: las "angostas lunas" de "filo empurpurado", la "cuchillería de un relámpago", el "fulgor del vino en los puñales" y el "bosque de lanzas y murenas".

\section{EL EMPALADO ${ }^{2}$}

1 Pero Caupolicán llegó al tormento.

2 Ensartado en la lanza del suplicio,

3 entró en la muerte lenta de los árboles.

4 Arauco replegó su ataque verde,

5 sintió en las sombras el escalofrio,

6 clavó en la tierra la cabeza,

7 se agazapó con sus dolores.

8 El Toqui dormía en la muerte.

9 Un ruido de hierro llegaba

10 del campamento, una corona

11 de carcajadas extranjeras,

12 y hacia los bosques enlutados

13 sólo la noche palpitaba.

14 No era el dolor, la mordedura

15 del volcán abierto en las vísceras,

16 era sólo un sueño del bosque,

17 el árbol que se desangraba.

18 En las entrañas de mi patria

19 entraba la punta asesina

20 hiriendo las tierras sagradas.

21 La sangre quemante caía

22 de silencio en silencio, abajo,

23 hacia donde está la semilla

24 esperando la primavera.

2 Pablo Neruda. Obras completas, p. 363. 
25 Más hondo caía esta sangre.

26 Hacia las raíces caía.

27 Hacia los muertos caía.

28. Hacia los que iban a nacer.

El tema histórico de Caupolicán es retomado por Neruda. Caupoliacán, según dice el primer verso, "llegó al tormento", esto es, llegó a la más trágica situación imaginable $y$, por lo tanto, situación sublime. En los dos versos primeros se emplean dos sinónimos: tormento y supli sio. Otro, martivio, va sobreentendido. El martirio por excelencia es el de Jesucristo que muere crucificado. Le sigue el de San Esteban, primer mártir del cristianismo. En cada caso, el suplicio parece tener cualidades purificadoras. Sufrir un tormento con resignación y entereza es característica de todos los grandes mártires de la historia. La muerte de Caupolicán tiene alguna semejanza con la muerte de Cristo. Ambos mueren en una intensa agonía de dolor. Jesucristo muere clavado a una cruz de madera. Caupolicán es clavado literalmente con una estaca de madera. La madera tiene, pues, un especial significado en ambas muertes. Pero lo más importante es que en los dos casos hay el contacto directo de la madera con la carne. Hoy la cruz de madera representa al Cristo, por sí sola. El Cristo en su agonía se convierte en cruz de tal manera, que cuando muere y es sepultado, la cruz sigue representándolo, sigue siendo Él.

Caupolicán, "ensartado en la lanza del suplicio", "entró en la muerte lenta de los árboles". A partir del tercer verso el poema es invadido por un mundo natural y elemental. Al entrar Caupolicán en "la muerte lenta de los árboles" hay una fusión entre la vida del cacique y la del árbol, o mejor aun, una fusión de estas dos vidas moviéndose lentamente hacia la muerte.

A continuación se produce una descripción con imágenes un tanto caóticas. "Arauco replegó su ataque verde". En este ataque verde toma parte Caupolicán. El verde y la tierra van a constituir elementos inseparables del árbol; los extremos del mismo. Caupolicán es parte del árbol, o es el árbol mismo que muere con él. ${ }^{3}$ Arauco en el escalof río

${ }^{3}$ Nótese que este ataque no es victorioso. Todo lo contrario; lo que hace Arauco es replegar el ataque y "clavar en la tierra la cabeza". Visualmente la imagen funciona en forma lógica dentro del poema. Los indios acostumbraban a cubrir sus cuerpos con ramas y hojas verdes para atacar sorpresivamente. Quizá haya una alusión indirecta y ya fuera del contexto al ataque "verde" de Mac$b e t h$, en donde todo un bosque avanza hacia la montaña. 
de las sombras clava en la tierra, identificándose con el árbol y con el propio Caupolicán, la cabeza, y se agazapa en sus dolores.

El empleo de la expresión "dormía en la muerte" y la utilización del verbo dormir sugieren la lentitud de la muerte. En realidad la muette producida al ser el torturado espetado en un palo puntiagudo por el recto es lenta. De ahí que la comparación funcione tan orgánicamente. Caupolicán muere tan lentamente como un árbol. Pero esta simple comparación va mucho más allá, pues la estaca sobre la cual se sienta Caupolicán es de madera y no es más que una parte del árbol, específicamente perfeccionada para esta forma de tortura y de muerte. De tal matuera, nơ va a seguir Caupolicán la muerte del árbol en una simple comparación, sino que, penetrado físicamente por el árbol, comienza él misमHO a convertirse en árbol y a seguir inevitablemente la lenta muerte de este último.*

Los españoles son los intrusos sanguinarios. Del campamento llega an "ruido de hierro", el ruido de las espadas o los cañones: armas metálicas de agresiớn. Mientras tanto, en los "bosques enlutados" sớlo la noche palpita. En una nueva personificación del elemento natural ${ }_{2}$ la nocbe palpita. Pero, por otra parte, los bosques permanecen "enlutados". Nueva alusión a la dualidad del hombre-árbol. El tuto se entiende lógicamente por la muerte inminente de Caapolicán. Pero son los bosques y

* La estrofa de La Araucana de Ercilla en que se describe la muerte de Caupolicán dice así:

No el aguzadó palo penetrante,
por más que las entrañas le rompiese,
barrenándơle el cuerpo, fue bastante
a que al dolor intenso se rindiese:
que, con sereno término y semblante,
sin que labio ni ceja retorciese,
sosegado quedó dé la manera
que si asentado en tálamo estuwiera.

Posiblemente Ercilla empleó el sustantivo tálamo como sinónimo de lecbo. Sin embargo, el tálamo es también parte de la flor. No creo que Ercilla haya estado pensando en este término botánico, pero si entendiéramos el sustantivo fálamer como parte de la flor y no como lecho, se ajusta también perfectamente al significado de la estrofa. El tálamo es el receptáculo de los verticilos de la flor. Los verticilos quedan asentados, utilizando el término de Ercilla, en este receptáculo. Caupolicán; encajado en la estaca de madera, queda asentadó en ese tálamo como el peristilo de una flor. El indio, ahora peristilo, se ha convertido en parte de un elemento natural, la flor. Si Neruda vio en los versos de $L a$ Araucana esta significación, se puede encontrar en el poema de Ercilla un antecedente muy preciso del poema de "El empalado".

5 La "corona de carcajadas extranjeras" parece aludir a la pasión de Cristo, quien también llevó una "corona" entre "carcajadas" de soldados romanos. 
no los hombres (aunque vaya implícita la idea) los que guardan luto por la muerte de un árbol.

Continúa esta integración de elementos humanos y elementos naturales no humanos. El volcán está abierto en las vísceras provocando el dolor. Pero ese dolor no importa. El uso del no al comenzar la negación inicial de la estrofa y la afirmación de que todo es "sólo un sueño del bosque", crean una atmósfera de fantasía e irrealidad que completa y refuerza el verso ocho: "El Toqui dormía en la muerte". En este "dormir en la muerte", en este "sueño del bosque", Caupolicán se va desangrando. La comparación ya sobra. A partir del verso 17 Caupolicán desaparece definitivamente. Es como una especie de transformación gradual, como un mimetismo progresivo. El indio es finalmente árbol. Pero algo inusitado ocurre. Al convertirse el caudillo en árbol, adquiere éste la propiedad humana de sangrar. La estrofa se cierra con "el árbol que se desangraba".

La siguiente estrofa tiene una dimensión patriótica. La punta que asesina a la patria, hiere las tierras sagradas. Caupolicán representa también las entrañas de la patria, lo más profundo y lo más genuino de su raza, la dueña verdadera del Arauco. Asociemos la punta asesina con la lanza del suplicio del verso 2 . La punta asesina hiere las tierras sagradas. Caupolicán es también parte inseparable de esa tierra como caudillo de su pueblo y como árbol.

La muerte se convierte en medio de vida. El proceso de la muerte del árbol-Caupolicán es irreversible. Pero la sangre que destila la víctima hará germinar la semilla que espera la primavera.

Aquí, la sangre quemante tiene una propiedad genética. La sangre cae hacia abajo, de silencio en silencio, como de peldaño en peldaño, alejándose cada vez más de la superficie donde muere el árbol. Se produce entonces un fuerte contraste en la estrofa, pues en la profundidad más absoluta aguarda la semilla que espera el efecto prodigioso de la sangre de la muerte para surgir a la primavera de la vida. Entiéndase que de esta semilla habrá de nacer un árbol.

Biológicamente y sin ver en la palabra primavera la connotación de vida, las semillas germinan y brotan como plantas en la primavera. El contraste que se produjo en esta estrofa entre la muerte del árbol y la nueva vida de la semilla, se repite en los versos finales. La sangre cae sobre los muertos, y después, produciendo el contraste, sobre los que iban a nacer. Claro que tenemos que ver el sentido más evidente: la sangre de Caupolicán convertido en árbol es fertilizante para los araucanos que 
aun no han nacido y a los cuales la muerte del cacique les servirá de estimulo para la lucha El empleo de la anáfora en los tres últimos versos, con la repetición de la preposición bacia, produce un efecto de continuidád relacionable con el fluir incesante de la sangre.

th La madera, que se convierte en elemento vital en este poema, es clemento vital para el propio Neruda; de ahí el valor significativo de la misma. En las confesiones que a manera de prólogo aparecen en la edición de las Obras completas, dice Neruda:

Pero los aserraderos cantaban. Se acumulaba la madera en las estaciones y de nuevo se olía a madera fresca en los pueblos. Por allá quedan unos versos míos escritos en las paredes. Me tentaban porque las tablas eran lisas como el papel, con venas misteriosas. Desde entonces la madera ha sido para mí, no una obsesión, porque no conozco las obsesiones, sino un elemento natural de mi vida.

...Ay, de cuanto conozco
y reconozco
entre todas las cosas
es la madera
mi mejor amiga,
yo llevo por el mundo
en mi cuerpo, en mi ropa
aroma
de aserradero,
olor de tabla roja,
mi pecho, mis sentidos
se impregnaron
en mi infancia
de árboles que caían
de grandes bosques llenos
de construcción futura,
yo sentí cuando azota
el gigantesco alerce,
el laurel alto de cuarenta metros...

Neruda ha asociado a la madera una serie de elementos presentes en la versión histórica de la muerte de Caupolicán y ha construido el poema

${ }^{6}$ Pablo Neruda, Obras completas, p. 24. 
por yuxtaposición $\mathrm{e}$ interpenetración de tales elementos. Es necesatio, al primcipio del poema, fijar de algún modo la noción de hombreastrbol, y esto lo hace Neruda en el verso 3. Así, desde los primeros versos Caupolicán "lega al tormento" como madera misma. Parece haber existido una especie de fatalidad histórica sentida por Neruda, pues Caupolicán se había convertido en Caudillo de los araucanos después de soportar sobre sus hombros un gigantesco tronco de madera. $Y$ en esto se identifica nuevamente Caupolicán con Cristo, quien llevó sobre los hombros la madera que - desde el momento en que la acepta- señala la muerte inevitable.

\section{CONCLUSTONES}

Al tratar el tenta de la vida y la muerte ambos poemas presentan idéntica visión del mismo. La muerte no es término sino elemento reproductor de vidas. La sangre de Caupolicán funciona como sustancia germinal que da vida a "los que iban a nacer". En el caso de "La muerte", el "cinturón de fósforo perverso" es un sistema citcular y necesariamente cíclico en el que cada vida no termina linealmente en la muerte, sino que la muerte, continuando el sentido direccional del trayecto inicial, va a ser a su vez nueva forma de vida.

En ambos poemas se va de lo particular a lo general (los elementos iniciales sirven para trazar amplias líneas conceptuales), de lo concreto a lo abstracto, o si se quiere, de lo material a lo "metafísico".

Lưs F. González Cruz

Penn State University

Ai New Kensigton, Pa. 